\title{
Early adenocarcinoma originating in submucosal gland of thoracic esophagus presenting as submucosal tumor
}
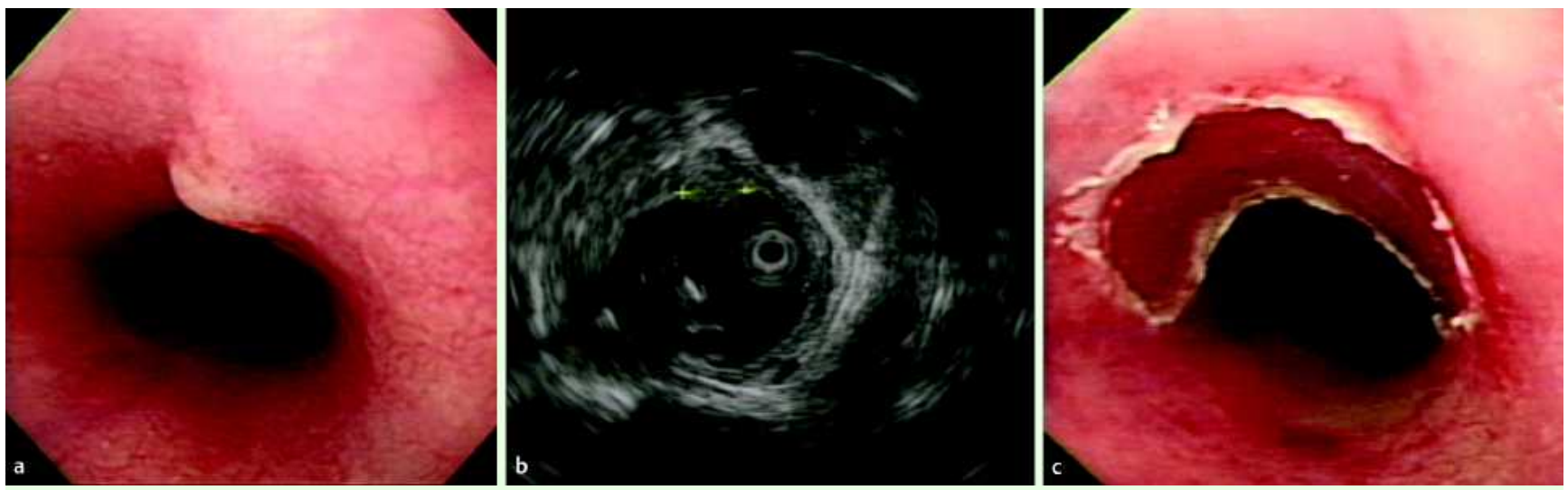

Fig. 1 Endoscopic images of the esophageal lesion. a Initial endoscopic appearance. b Endoscopic ultrasound image. $\mathbf{c}$ Endoscopic appearance after mucosectomy.
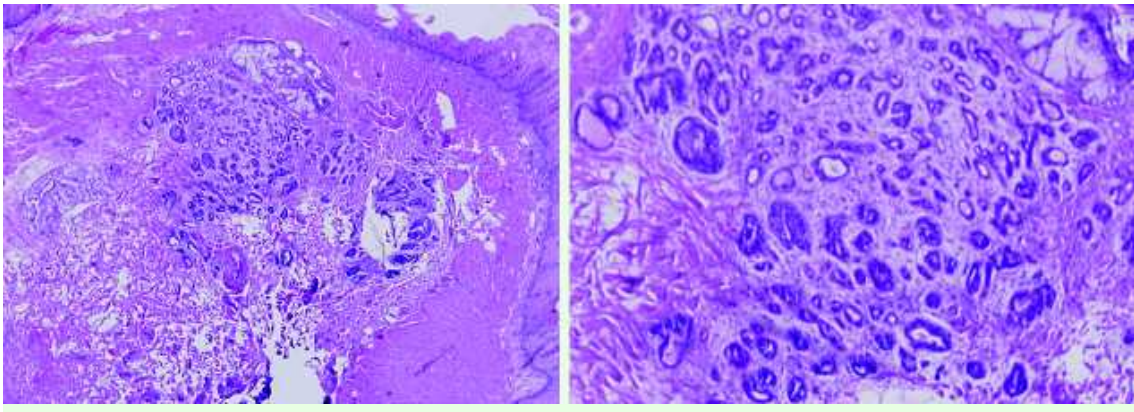

Fig. 2 Histopathological analysis showed a tubular adenocarcinoma arising in the submucosal glands (H\&E stain; $\times 40)$.

The most common malignant neoplasm of the esophagus is squamous cell carcinoma. The majority of adenocarcinomas of the esophagus originate in the esophagogastric junction, Barrett's esophagus, or ectopic gastric mucosa [1]. Adenocarcinoma arising in a submucosal gland of the esophagus beneath the squamous epithelium is rare [2].

A 43-year-old woman with an esophageal submucosal lesion about $1 \mathrm{~cm}$ in size, located $24 \mathrm{~cm}$ from the incisors ( $\bullet$ Fig. 1 a), underwent endoscopic ultrasonography that revealed an isoechoic lesion about $0.5 \mathrm{~cm}$ in size over the deep mucosal and submucosal layers of the esophageal wall (॰ Fig. 1 b)

The patient underwent endoscopic mucosal resection using the cap method (EMRC) without complications (॰ Fig. $1 \mathrm{c}$ ).
The resected specimen measured $1 \times 0.5 \times 0.5 \mathrm{~cm}$. Microscopically, a submucosal tumor composed of distorted tubular glands with an infiltration growth pattern was noted. The tumor was confined to the submucosa without involvement of either overlying epithelium or muscularis propria. Diagnosis was a tubular adenocarcinoma arising in the submucosal glands ( $\bullet$ Fig. 2).

After an explanation of the risks of possible aggressive behavior of adenocarcinoma of the esophagus, the patient still refused surgery or adjuvant radiation therapy. To date (18 months of follow-up), there has been no evidence of recurrence or metastasis.

There were some concerns: increased depth of tumor invasion increases the risk of lymph node metastases [3], and endoscopic therapy for tumors with submucosal invasion may overlook this risk.
Therefore, there are still debates about endoscopic mucosal resection as a treatment for early esophageal cancer $[4,5]$. In our reported case, the adenocarcinoma arose in the submucosal gland, not in epithelium. The definition of this tumor as "early stage" may be somewhat controversial.

In this case, we considered that local treatment alone was not contraindicated, since both endoscopic image and pathological section showed complete resection, and endoscopic ultrasonography and chest CT scan gave no evidence of lymph node metastasis.

Endoscopy_UCTN_Code_CCL_1AB_2AC_3AB

\section{S.-W. Wang ${ }^{1}$, C.-S. Chang ${ }^{1,4}$, J. Wang ${ }^{2}$,}

\section{H.-Z. Yeh ${ }^{1,3}$}

Division of Gastroenterology, Taichung Veterans General Hospital, Taichung, Taiwan

2 Department of Pathology, Taichung Veterans General Hospital, Taichung, Taiwan

School of Medicine, National Yang Ming University, Taipei, Taiwan

${ }^{4}$ Institution of Medicine, Chung Shan Medical University, Taichung, Taiwan 
References

1 Christensen WN, Sternberg SS. Adenocarcinoma of the upper esophagus arising in ectopic gastric mucosa. Two case reports and review of the literature. Am J Surg Pathol 1987; 11: 397-402

2 Endoh Y, Miyawaki M, Tamura G et al. Esophageal adenocarcinoma that probably originated in the esophageal gland duct: a case report. Pathol Int 1999; 49: 156-159

3 Shimada $H$, Nabeya $Y$, Matsubara $H$ et al. Prediction of lymph node status in patients with superficial esophageal carcinoma: analysis of 160 surgically resected cancers. Am J Surg 2006; 191: 250-254

4 Pech O, May A, Gossner L et al. Curative endoscopic therapy in patients with early esophageal squamous-cell carcinoma or high-grade intraepithelial neoplasia. Endoscopy 2007; 39: $30-35$

5 Rahden BH von, Stein HJ. Endoscopic mucosal resection as curative therapy for esophageal cancer is inappropriate and should be discouraged. Endoscopy 2008; 40: 169
Bibliography

DOI $10.1055 / \mathrm{s}-2008-1077680$

Endoscopy 2008; 40: E237-E238

(c) Georg Thieme Verlag KG Stuttgart · New York . ISSN 0013-726X
Corresponding author

\section{H.-Z. Yeh, MD}

Division of Gastroenterology,

Taichung Veterans General Hospital No. 160, Sec. 3, Chung-Kang Road

Taichung

Taiwan

Fax: +886-4-23741331

yhz@vghtc.gov.tw 